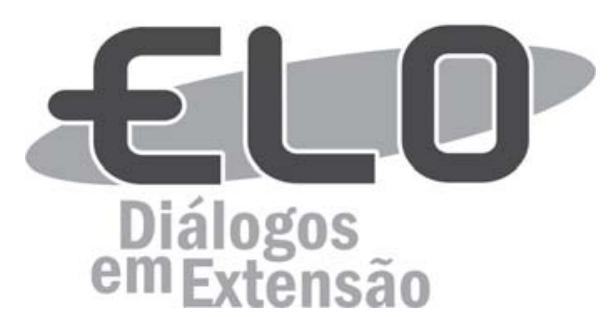

\title{
(Re)desenhando o trabalho com/para surdos em Viçosa: contribuições do projeto Surdo Cidadão da UFV
}

\author{
Eduardo Andrade Gomes ${ }^{1}$, Ana Paula Abrantes ${ }^{2}$, Cristiane Botelho Valadares ${ }^{3}$
}

\begin{abstract}
Resumo: A grande maioria das pessoas surdas possui um histórico de vida marcado por preconceito e restrições, sobretudo em relação à comunicação. Isso se deve ao fato da sociedade ainda estar atenta apenas a questões clínicas e não valorizá-los enquanto indivíduos plurais capazes de se desenvolverem por meio da Lingua de Sinais. Em função dessas equivocadas concepções, o Projeto Surdo Cidadão tem por objetivo divulgar e ensinar, por meio de minicursos em nivel básico, a Lingua Brasileira de Sinais (Libras) aos ouvintes; promover e orientar, por intermédio de palestras e oficinas, estudantes, professores e funcionários da Universidade Federal de Viçosa e da própria cidade a respeito de algumas nuances da Libras e cultura surda; e ainda desenvolver atividades de Química e Matemática de cunho educacional voltado à estudantes surdos de Viçosa e região que cursam o Ensino Médio ou que já concluíram. Por isso, nesse relato serão explanadas as ações que foram realizadas em 2015 no projeto visando uma conscientização à população sobre as pessoas surdas.
\end{abstract}

Palavras-chave: Ações em Viçosa. Projeto Surdo Cidadão. Surdos.

Área Temática: Educação.

\section{(Re)designing work with / for the deaf in Viçosa: project contributions Deaf Citizen UFV}

\begin{abstract}
The vast majority of deaf people has a history of life marked by prejudice and restrictions, especially in relation to communication. This is because the company still be attentive only to clinical issues and not value them as plural individuals able to develop by means of Sign Language. Due to these misconceptions, the Deaf Citizens Project's performance parameter disseminate and teach through express courses to Brazilian Sign Language (Libras) to listeners, promote and guide through lectures and student, teachers workshops, faculty and staff the Federal University of Viçosa and the city itself about some aspects of Libras and deaf culture, and develop activities Chemistry and Mathematics educational nature aimed at deaf students Viçosa and region who attend high school or already completed. Therefore, this report will be explained about these actions carried out in 2015 in the project aimed at raising awareness of the deaf people.
\end{abstract}

Keywords: Actions in Viçosa. Project Citizen Deaf. Deaf.

\section{Proyecto El (re)diseño de trabajo con / para los sordos en Viçosa: contribuciones del proyecto Sordo Ciudadano en la UFV}

Resumen: La gran mayoría de las personas sordas tienen una historia de vida marcada por los prejuicios y restricciones, especialmente con relación a la comunicación. Esto se debe a que la sociedad todavía esté atenta únicamente a los aspectos clínicos y no los valora como individuos plurales capaces de desarrollarse a través de la lengua de signos. Debido a estos conceptos erróneos, el Proyecto Ciudadanos Sordos pretende difundir y enseñar, a través de cursos cortos en un nivel básico, a la Lengua Brasileña de Señales (Libras) a los oyentes;

\footnotetext{
${ }^{1}$ Universidade Federal de Viçosa. Rua Tenente Kummel, 97/104, Centro, Viçosa. (31)985775216. edu.gomes06@gmail.com.

${ }^{2}$ Universidade Federal de Viçosa.
}

${ }^{3}$ Universidade Federal de Viçosa. Coordenadora do Projeto de Extensão Surdo Cidadão. 
promover y orientar a través de conferencias y talleres para estudiantes, profesores y empleados de la Universidad Federal de Viçosa y de la respectiva ciudad algunos matices de Libras y cultura de los sordos, y desarrollar actividades de Química y Matemáticas de naturaleza educativa dirigida a los estudiantes sordos de Viçosa y de la región que estudian en la escuela secundaria o ya lo han terminado. Por lo tanto, se desarrollará este informe acerca de estas acciones llevadas a cabo en 2015 en el proyecto, que tendría como objetivo la búsqueda de una toma de conciencia de la población sobre las personas sordas.

Palabras clave: Acciones en Viçosa. Proyecto Ciudadanos Sordos. Sordos.

\section{Introdução}

Desde a formação e constituição das primeiras comunidades humanas, uma característica marcante, mas que talvez passe despercebida por muitos, se trata da diversidade. Isso significa que todos são diferentes e diversos em suas experiências e valores (CUNHA, 2014). Contudo, justamente por essa questão ser invisível aos olhos de alguns, a mesma sociedade que é plural por natureza, convencionou/convenciona normas e padrões a serem adotados.

É importante perceber que norma é semelhante a uma regra, algo que regulamenta e é regulamentado, que domina e pode ser dominado. Assim, segundo Foucault (1999 apud Lopes e Fabris, 2013), a norma pode ser cultivada tanto a um indivíduo como a um grupo. Desse modo, as normas induzem entendimentos e práticas que homogeneízam as pessoas ou geram atos que exaltam as diferenças a partir de menções preestabelecidas por um meio, isto é, elas podem deliberar um ou mais modelos ou estereótipos a serem adotados (LOPES; FABRIS, 2013). E por ter que seguir o modelo das pessoas ouvintes, tidas como normais, os surdos durante um longo tempo foram grosseiramente estigmatizados pela sociedade, sendo impedidos de possuir ou herdar propriedades, casar-se, dirigir, votar como os demais cidadãos, dentre outras. Essas proibições se davam por estas serem consideradas pessoas incapazes e sem pensamento, já que não conseguiam se comunicar da mesma forma que os ouvintes.

Com o passar dos anos, houve várias tentativas em busca de se educar os surdos. Uma delas foi a aplicação de algo parecido com um alfabeto manual pelo espanhol Juan Pablo Bonet em 1620 e os sinais metódicos do abade Charles Michel L'Epée em 1750. Esses sinais metódicos se firmavam como uma combinação entre a Língua de Sinais e a língua oral francesa. Entretanto, em 1880 realizou-se um congresso em Milão, na qual os surdos foram obrigatoriamente oralizados, isto é, deveriam adquirir e desenvolver a língua oral e as habilidades de fala e audição, com o intuito de se igualarem linguisticamente aos ouvintes. Tal opressão às Línguas de Sinais perdurou por um longo período, trazendo uma série de consequências sociais e educacionais equivocadas (GOMES, 2015).

Segundo Quadros (2003), o desenvolvimento dos surdos ao tentar adquirir a língua oral foi um fracasso. Ao tentar suprir esse déficit no processo de aquisição de linguagem, surgiu-se uma nova filosofia educacional, a comunicação total. Nela se utilizava de todas as formas e meios de comunicação concomitantes à língua oral, seja pelo uso de sinais, seja pelo uso de gestos, seja pelo uso de objetos. Buscando desenvolver as potencialidades linguísticas dos indivíduos surdos, surge outra abordagem educacional, o bilinguismo, cujo foco era a evolução dos surdos na Língua de Sinais como língua natural e a língua escrita do país de origem como segunda língua (CAPOVILLA, 2000).

Em 1857, a pedido de Dom Pedro II, o professor surdo francês E. Huet veio ao Brasil e fundou a primeira escola para Surdos, chamada "Instituto Imperial dos Surdos-Mudos", atualmente "Instituto Nacional de Educação dos Surdos - INES". Foi a partir deste instituto e dos ensinamentos desse professor que a Língua Brasileira de Sinais começou a ser sistematizada, recebendo uma forte influência da Língua de Sinais Francesa. Por volta de 1875, o ex-aluno do INES, Flausino José da Costa Gama publicou o livro intitulado "Iconografia dos Signaes dos Surdos-Mudos" que apresentava por meio de desenhos e explicações os sinais utilizados pelos surdos nessa instituição (SOFIATO; REILY, 2012). Evidentemente, com o passar dos anos, os surdos brasileiros foram se apropriando da língua e a mesma foi adquirindo traços e identidades culturais, se desvinculando da Língua de Sinais Francesa.

Apesar de todo esse histórico, muitas pessoas acreditavam, e ainda acreditam, que a forma como os surdos se comunicam é apenas por meio de um agrupamento de gestos aleatórios. Por isso, por volta de 1960 o linguista americano William Stokoe buscou compreender e pesquisar o modo como as comunidades surdas dos Estados Unidos interagiam entre si. Através desses estudos, ele percebeu que realmente se tratava de uma língua natural e espontânea, realizada em modalidade visuo-espacial e 
constituída pelos mesmos níveis linguísticos (fonológicos, morfológicos, sintáticos, semânticospragmáticos) que as línguas orais-auditivas. Além disso, essas línguas são comparáveis em complexidade e expressividade, permitindo discutir quaisquer assuntos como poesia, filosofia, política, entre outros.

No Brasil, a Libras foi reconhecida como primeira língua da comunidade surda a partir da Lei 10.436/02, além de enfatizar que a Língua Portuguesa escrita seria a segunda língua para esses cidadãos (BRASIL, 2002). Todavia, a Língua Brasileira de Sinais não é a Língua Portuguesa sinalizada, já que apresenta uma estrutura lexical e gramatical própria. Regulamentando esse documento, tem-se o Decreto 5.626 no qual são ressaltadas ações, formações e capacitações de profissionais a atuarem como instrutores e professores de Libras, tradutores e intérpretes de Libras - Língua Portuguesa, a inserção de uma disciplina de Libras em cursos superiores de Licenciaturas, Educação Especial e Fonoaudiologia, além de destacar a possibilidade de uma educação em escolas ou classes bilíngues. $\mathrm{O}$ trabalho na perspectiva de uma educação bilíngue para surdos prevê o uso da Língua de Sinais como primeira língua para instrução e a Língua Portuguesa escrita como segunda língua, incorporadas em um processo mais amplo atendendo a um currículo, didática e metodologias reorganizadas visualmente.

A maioria dos surdos, cerca de $95 \%$, é oriunda de uma família de ouvintes, o que os leva ao não aprendizado da Libras desde a mais tenra idade, já que essas famílias, seja por preconceito ou falta de orientação, tendem a lutar pelo exercício unicamente da língua oral. Entretanto, o ideal para essas crianças e jovens seria o aprendizado da Língua de Sinais o mais cedo possível para que possam se constituir em cultura e identidade enquanto surdos (DALCIN, 2006).

A grande dificuldade em adquirir essa língua se deve, principalmente, ao não contato constante entre si e a não institucionalização de uma disciplina de Libras nas escolas, por exemplo, o que seria um fator determinante para difusão e ensino da Língua de Sinais para crianças e jovens ouvintes como segunda língua e como primeira língua para os estudantes surdos. Neste sentido, observa-se que a população em geral ainda não possui (in)formações que possam auxiliá-los na comunicação com/ entre os surdos, mesmo havendo uma lei que preconize e legitime a Libras enquanto uma das línguas oficiais do país.

Por isso, o projeto Surdo Cidadão tem o objetivo de promover a difusão e problematizar essas questões quanto à importância da língua por meio de palestras e minicursos, além de oficinas didáticas direcionadas ao público surdo, contribuindo para que venham alcançar sucesso no processo educacional e no mercado de trabalho.

\section{Firmando ações em Viçosa e Região}

Considerando os pressupostos apontados anteriormente, em 2007 foi implementado um projeto de extensão na Universidade Federal de Viçosa - UFV nomeado a princípio por "Matemática e Surdez: Questão de Linguagem e Novas Técnicas de Ensino" e posteriormente por "Surdo Cidadão", cujo objetivo sempre foi desenvolver e apoiar atividades que visem: divulgar, difundir, ensinar e conscientizar sobre a importância da Língua Brasileira de Sinais, além de dar suporte didático em Química e Matemática a estudantes surdos, possibilitando aos mesmos uma melhor relação comunicativa com os ouvintes e um consequente acesso aos benefícios do convívio em sociedade e apropriação de conhecimento científico.

Desse modo, a seguir, será relatado algumas ações do projeto no ano de 2015 sobre as aulas de Química e Matemática lecionadas pelos bolsistas aos estudantes surdos, os minicursos de Libras ministrados por um colaborador surdo viçosense e as palestras e oficinas proferidas também pelos bolsistas.

\section{Aulas de Química e Matemática}

Durante o ano de 2015, as aulas de Química e Matemática foram realizadas semanalmente, com duração de duas horas cada uma, entre os meses de março e dezembro. As aulas ocorreram no Laboratório Interdisciplinar de Formação de Professores (LIFE) e no Laboratório de Ensino em Matemática no Prédio das Licenciaturas da UFV. Ambos locais favoreceram as atividades por possuírem instalações adequadas quanto à disposição das cadeiras, mesas e quadro, além dos materiais visuais e concretos utilizados. Esses materiais são capazes de ser manuseados e conseguem representar a ideia 
discutida em sala de aula, proporcionando maior dinamismo e participação dos estudantes, além de despertar a curiosidade, a observação e a atenção. Todas as aulas foram ministradas em Libras, sendo as de Química por dois bolsistas licenciandos em Química da UFV e as de Matemática por uma licenciada e graduanda em bacharelado em Matemática pela mesma instituição.

Ao longo do referido ano, o público-alvo foi composto de seis a oito estudantes surdos que já haviam concluído o Ensino Médio, porém não tiveram uma apreciável formação básica, principalmente por suas respectivas escolas não possuírem intérpretes de Libras- Língua Portuguesa e pelos professores não obterem formação metodológica adequada para contemplar esses estudantes em sala de aula. Assim, esse processo de escolarização não possibilitou, de fato, um desenvolvimento acadêmico e, até mesmo, social (SLOMSKI, 2010). Diante dessa situação, os estudantes com necessidades educacionais especiais, por fazerem parte do quadro de discentes da escola são prejudicados pela falta de estrutura formativa e pedagógica da comunidade escolar. Todavia, apenas inserir esses estudantes em salas de aula sem qualquer reorganização se configura como integração e não inclusão (MANTOAN, 2006).

No projeto, as aulas teóricas, práticas e as atividades de ensino realizadas foram pensadas reconhecendo as especificidades inerentes à comunidade surda, desde aspectos envolvendo estratégias visuais como materiais concretos, imagens, vídeos, animações, experimentos até o uso da Língua de Sinais como instrução e mediação do professor, com enfoque no Exame Nacional do Ensino Médio (ENEM). Essas aulas, selecionadas e elaboradas pela coordenadora e os bolsistas do projeto, se basearam em torno do tema gerador "Alimentação". Na área da Química, abordaram-se questões contextualizadas relacionadas a lipídeos, carboidratos, proteínas, sais minerais e vitaminas focando em pontos que possibilitem uma assimilação de ideias desse assunto. Já nas aulas de Matemática, destacaram-se transformações de unidades de medida, como metro e seus múltiplos, volume, tempo, massa e operações básicas de multiplicação e divisão para fixar, principalmente, os algoritmos destas operações. Conforme já mencionado, as aulas foram ministradas em Libras como primeira língua e foram realizados alguns exercícios de modo que pudessem utilizar também a Língua Portuguesa escrita traçando um caminho educacional bilíngue. Isso se torna importante, já que necessitam ter competência também nessa língua. O principal objetivo dessas atividades foi possibilitar a esses estudantes surdos a compreensão de conceitos que são significativos para suas vidas, que lhes dê subsídios para galgarem novos horizontes e possibilitar o ingresso no ensino superior (VIEIRA-MACHADO, 2008).

\section{Minicursos de Libras}

Os minicursos oferecidos pelo projeto Surdo Cidadão tem o objetivo de difundir e ensinar a Libras para a sociedade. Durante o ano de 2015 foram oferecidos seis minicursos, ministrado por um colaborador surdo viçosense, com ajuda dos bolsistas do projeto que atuaram como intérpretes entre surdos e ouvintes. Todos os minicursos foram de nível introdutório, com o intuito de despertar e incentivar o interesse das pessoas para que possam buscar cursos mais avançados na língua e aprofundar seus estudos na mesma.

A parte teórica do curso foi apresentada pelos bolsistas, na qual foram abordados os mitos e crenças sobre as Línguas de Sinais, como a universalidade e artificialidade, gestualidade aleatória, expressividade quanto a conceitos abstratos, uso apenas do alfabeto manual e quanto à escrita nessa língua. Trabalhou-se a estrutura linguística apresentando os cinco parâmetros fonológicos: configuração de mão, ponto de articulação, movimento, orientação da palma da mão e expressões não-manuais. Abordaram-se também algumas questões envolvendo a terminologia (surdo, surdomudo e deficiente auditivo), leitura labial, aparelhos auditivos e a discussão do bilinguismo para a formação do sujeito surdo. Já a parte prática foi ministrada pelo colaborador surdo focando no vocabulário dos sinais: alfabeto, números, calendário, tempo, família, cores, profissões, verbos, adjetivos, informática e frutas.

Esses minicursos atenderam, ao longo do ano, em torno de 147 pessoas, sendo eles $76 \%$ estudantes, $12 \%$ professores, $3 \%$ pedagogos, $3 \%$ profissionais da área da saúde (enfermeiros, médicos), $2 \%$ supervisores escolares, $2 \%$ fotógrafos e $2 \%$ outros profissionais.

No gráfico a seguir é apresentada uma avaliação feita, via questionário, com os participantes dos minicurso, no intuito de orientar a equipe coordenadora quanto à objetividade e pertinência dessa atividade. 


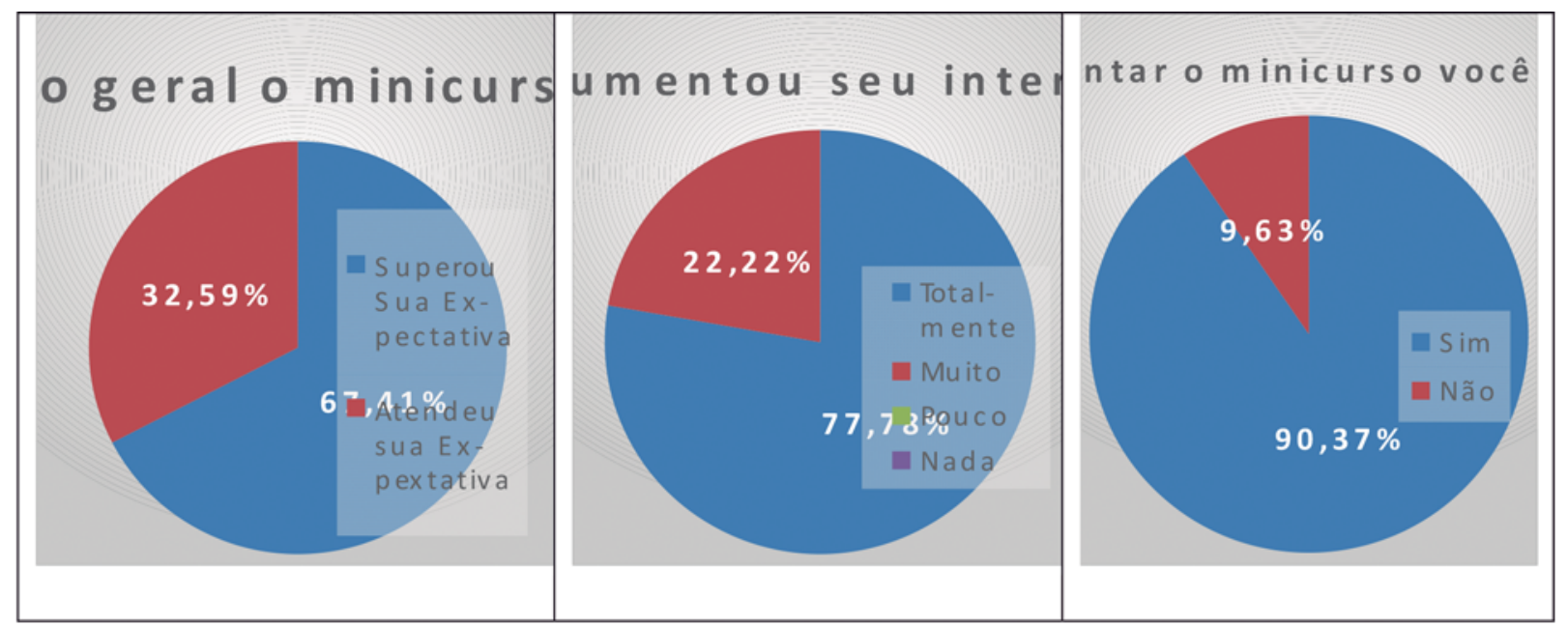

Figura 01: Avaliação dos participantes do minicurso.

Fonte: Elaborada pelos autores a partir de um questionário.

\section{Palestras e Oficinas}

As palestras e oficinas, também oferecidas pelo projeto, tem o objetivo de despertar o interesse das pessoas, além de promover e orientar estudantes, professores e funcionários da Universidade e da cidade de Viçosa a respeito da Língua Brasileira de Sinais e da cultura surda. Ao longo do ano de 2015, as palestras atenderam, em torno de 163 pessoas de diversas áreas, por exemplo, estudantes de Física, Matemática, Química, Biologia e Geografia. Os temas abordados nas palestras foram os mitos e crenças da língua, a estrutura gramatical e alguns pontos como a terminologia, leitura labial e aparelhos auditivos.

As oficinas são proporcionadas à comunidade e, em 2015, foram ofertadas em uma escola pública de Viçosa. Essa abrangeu o conteúdo básico sobre Libras, bem como seus mitos e crenças e alguns recursos tecnológicos que permitem encontrar e aprender sinais da língua, por exemplo, aplicativos para celular como "Hand Talk", "Prodeaf" e dicionário online "Acesso Brasil".

\section{Considerações Finais}

A ausência de uma política social mais efetiva para difusão e aprendizagem da Libras para pessoas surdas e ouvintes ${ }_{\iota}$ nos motiva a tentar aprimorar as atividades e ações propostas pelo projeto Surdo Cidadão. Por isso a intenção é continuar ofertando os minicursos, palestras e oficinas para a comunidade em geral e também as aulas de Química e Matemática para os estudantes surdos.

Através dessas aulas, percebemos o quanto esses estudantes vêm conseguindo estruturar melhor as ideias e compreender por meio das Ciências da Natureza e Matemática o cotidiano em que vivem. Até o início de 2016, nenhum deles ingressou no ensino superior, mas é notório o crescimento pessoal e inclusive nas notas do ENEM se comparadas aos anos anteriores. Tais afirmativas são pertinentes, por realizarmos um acompanhamento individual desses estudantes.

Ademais, o projeto também dá possibilidade dos próprios bolsistas se reinventarem e se formarem ao exercerem movimentos conjuntos aos surdos utilizando a Língua Brasileira de Sinais e metodologias visuais.

\section{Fontes de Financiamento}

PROEXT (MEC-UFV) e PIBEX (UFV).

\section{Agradecimentos}

A todas as pessoas surdas e ouvintes que participaram e/ou participam das atividades do projeto. 


\section{Referências Bibliográficas}

BRASIL. Lei 10.436. Dispõe sobre a Língua Brasileira de Sinais - Libras e dá outras providências. Diário Oficial da União. Brasília, 24 de abril de 2002.

CAPOVILlA, F. C. Filosofias Educacionais em Relação ao Surdo: Do Oralismo à Comunicação Total ao Bilinguismo. Revista Brasileira de Educação Especial, v.6, n.1, 2000.

CUNHA, A. E. Práticas pedagógicas para inclusão e diversidade. Rio de Janeiro: Wak Editora, 2014.

DALCIN, G. Um estranho no ninho: um estudo psicanalítico sobre a constituição da subjetividade do sujeito surdo. In: QUADROS, R. M. (Org). Estudos Surdos I. Petrópolis: Editora Arara Azul, 2006.

FRYDRYCH, L. A. K. O estatuto linguístico das Linguas de Sinais: A Libras sob a ótica saussuriana. Dissertação de mestrado em Teorias do texto e do discurso. Universidade Federal do Rio Grande do Sul, Porto Alegre, 2013.

GOMES, E. A. Estudo da inferência semântica-pragmática do termo Energia a partir da tradução interlingual em aulas de Termoquímica com estudantes surdos. Monografia do curso Licenciatura em Química. Universidade Federal de Viçosa, Viçosa, 2015.

LOPES, M. C.; FABRIS, E. H. Inclusão \& Educação. Belo Horizonte: Autêntica Editora, 2013.

MANTOAN, M. T. E. Inclusão escolar: o que é? Por quê? Como fazer? São Paulo: Moderna, 2006.

QUADROS, R. M. Situando as Diferenças Implicadas na Educação de Surdos: Inclusão/Exclusão. Ponto de Vista, Florianópolis, n.5, p. 81-111, 2003.

SLOMSKI, V. G. Educação Bilíngue para surdos: concepções e implicações práticas. Curitiba: Editora Juruá, 2010.

SOFIATO, C. G.; REILY, L. Justaposições: o Primeiro Dicionário Brasileiro de Língua de Sinais e a Obra Francesa que Serviu de Matriz. Revista Brasileira Educação Especial, v.18, n.4, p. 569-586, 2012.

VIEIRA-MACHADO, L. M. C. Narrar e pensar as narrativas surdas capixabas: o outro surdo no processo de pensar uma pedagogia. In: QUADROS, R. M. (Org). Estudos Surdos III. Petrópolis: Editora Arara Azul, 2008.

Recebido para publicação em 17/3/2016 e aprovado em 12/12/2016. 